\title{
Awareness of Oral Cancer Among Dental Students - A Survey
}

\author{
Harshinee Chandrasekar ${ }^{1}$ and Jayanth Kumar Vadivel ${ }^{2}$ \\ ${ }^{1}$ Saveetha Dental College and Hospital, Saveetha Institute \\ of Medical and Technical Sciences, Saveetha University, Chennai, Tamil Nadu, India. \\ ${ }^{2}$ Reader, Department of Oral Medicine, Saveetha Dental College and Hospital, Saveetha \\ Institute of Medical and Technical Sciences, Saveetha University, Chennai, Tamil Nadu, India.
}

\section{ABSTRACT}

Oral cancer represents one of the most common malignancies. The objective of this survey was to assess the awareness and determine the understanding of oral cancer among dental students This study was conducted based on a questionnaire which consist of 10 questions through a web-linked application called Survey Monkey. A puposive random sample size of 100 dental students from Chennai participated in the study. The overall awareness of oral cancer was good with the vast majority being aware of the family history, role of Human Papilloma Virus(HPV), screening aids for oral cancer. A statistical analysis was done with SPSS to look for gender based differences and it was found there was a statistically significant difference in between the genders for the common site of oral cancer and the role played by HPV. As a conclusion, the majority of the dental students within the study were aware of the term oral cancer. However, this study was limited to one particular institute. Further, study should be conducted in a larger scale area and sample size to get a proper overview regarding this topic within the general public concerning the new advent technologies.

\section{KEY WORDS: ORAL CANCER; HPV; AWARENESS; SQUAMOUS CELL CARCINOMA.}

\section{INTRODUCTION}

Oral cancer represents one of the most common cancers in our population. It most often occurs due to improper life style and adverse habits. According to WHO research an approximate of 20,000 deaths annually worldwide and around 4,600 deaths were occurring in India due to this oral cancer. There is a significant difference in the incidence of oral cancer in different regions of the world. As a result of many publications regarding oral cancer incidences compared according to the gender level, had shown that highest incidences in India constituting

\section{ARTICLE INFORMATION}

*Corresponding Author: doctorjayanth@gmail.com Received 7th Aug 2020 Accepted after revision 24th Sep 2020 Print ISSN: 0974-6455 Online ISSN: 2321-4007 CODEN: BBRCBA

Thomson Reuters ISI Web of Science Clarivate Analytics USA and Crossref Indexed Journal

\section{Clarivate
Analytics}

NAAS Journal Score 2020 (4.31) SJIF: 2020 (7.728)

A Society of Science and Nature Publication,

Bhopal India 2020. All rights reserved.

Online Contents Available at: http//www.bbrc.in/

Doi: http://dx.doi.org/10.21786/bbrc/13.8/156 around $60 \%$ of all cancers in men and $40 \%$ of all cancers among women(Jemal et al. 2010).

Though there have been severa advances in the detection and treatment of cancer, Oral cancer carries a very low five year disease free survival rate of around 50\%. Earlier diagnosis greatly increases the patient's chances of survival as the mouth is very accessible for a clinical or self-examination(Agrawal et al. 2012). Yet, most of the oral cancer namely squamous cell carcinoma is frequently diagnosed in advanced stages due to lack of awareness among the public and lack of health education campaigns in rural area of India(Monteiro et al. 2012).

Oral cancer usually begins with a primary ulcer originating from the oral tissue. It has a high tendency to metastasize to regional lymph nodes. There are numerous kinds of oral cancer, but approximately 90\% are squamous cell carcinoma arising in the tissues that line the oral cavity and labial tissues. 
Squamous cell carcinoma is epithelial in origin and is malignant whereas other tumour-like angio-sarcoma is mesenchymal in derivation and is also malignant(Srikanth Reddy et al. 2012). Squamous cell carcinoma usually occurs in sites like the floor of the oral cavity, buccal mucosa, gingiva(gums), lips, and palate (Hassona et al. 2015). The etiology of squamous cell carcinoma depends on numerous factors. It is divided into two groups which are extrinsic or intrinsic. The extrinsic factors are smoking, smokeless tobacco, actinic radiation, infection, alcohol or sexually transmitted infection like syphilis or radiation whereas, the intrinsic reasons or which act as co-factors are nutritional deficiency like iron deficiency anemia.(Kumar et al. 2016).

Apart from epithelial malignancies, there are also cancers arsing from salivary gland tissues adenocarcinoma resulting from a main salivary gland, lymphoma from lymph nodes and further lymphoid tissues, or melanoma from the pigment-producing cell of oral mucosa(Prasad 2014). Oral squamous cells carcinoma has diverse medical appearance including, exophytic mass appearance with papillary and verruciform growth, whereas an endophytic ulcerations also can be seen. Most of the oral cancers precede a precursor lesion. The most precursor lesion presents with a clinically white non-scrapable patch referred to as leukoplakia and erythroplakia which appears as a red patch and erythroleukoplania which presents as a red and white patch.(Ramachandra 2012). The oral cancer when it involves the bone presents as a moth-eaten radio-lucency with ill defined boundaries.

The treatment of oral cancer is predominantly surgical followed by radiotherapy. Nevertheless most cases of oral cancer are diagnosed late due to the lack of pain in the early stages and inadequate knowledge on the presentation of oral cancer. These reasons cumulatively make oral cancer one of the most common diseases in our country.(Ariyawardana and Vithanaarachchi 2005). Our recent research have features as numerous articles in reputed journals(Subramaniam and Muthukrishnan 2019; Vadivel et al. 2019; Santosh Rayagouda Patil et al. 2020; Santosh R. Patil et al. 2018; S. R. Patil et al. 2018). Based on this experience we planned to pursue a study to evaluate the awareness of knowledge about oral cancer among Dental students.

Figure 1: Bar chart showing the distribution of the gender among the respondents. 72 were females and 28 were males

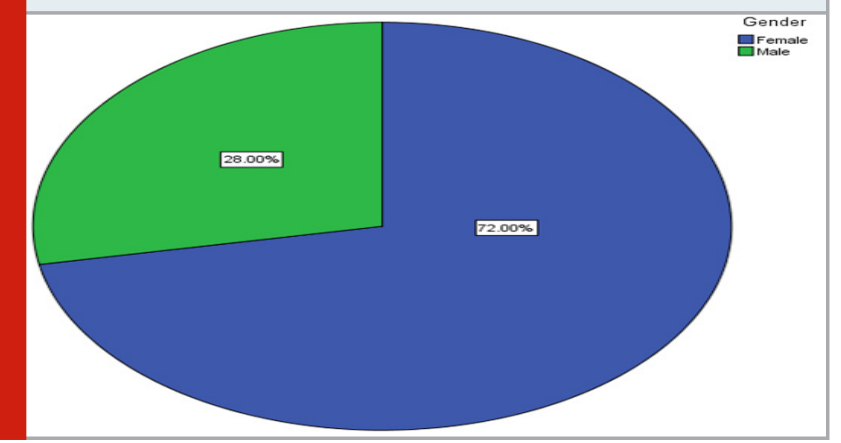

308

\section{MATERIAL AND METHODS}

The survey consisted of using a close ended questionnaire. A set of 10 questions were prepared by the authors and were pre validated by two senior faculties in the Department. Based on the comments received during the prevalidation phase the options were slightly modified and the final questionnaire was prepared. A total of 100 dental students were selected based on the purposive random sampling from a private Dental Institution in Chennai. The questionnaire was circulated online using Survey Monkey.

Inclusion criteria: The Inclusion criteria was Interns from one Dental Colleges and who had a expressed a willingness to be a part of the survey.

Exclusion criteria: The students who were not willing to be a part of the survey were excluded.

Though the name, age and gender of the participants were collected during the survey, the name and age were not used for any discriminatory purpose in the survey and a strict confidentiality of the names of the students were maintained during the study. The responses received were extracted in the form of an excel worksheet. In this worksheet data encoding was done and was imported into SPSS ver 21. Here the basic descriptive statistics was worked out for each question and the final inferential statistics looking for an association between the gender and the nature of responses was done using Chi-square analysis.

Figure 2: Bar graph showing association between the awareness of oral cancer and the gender of the participants. $61 \%$ of the respondents were aware that family history was an etiological factor in the causation of oral cancer. A Chi-square association between the gender and the response $(0.176 \mathrm{p}-0.674(\mathrm{p}>0.05))$ which is not statistically significant implying no association between the gender and the nature of response.

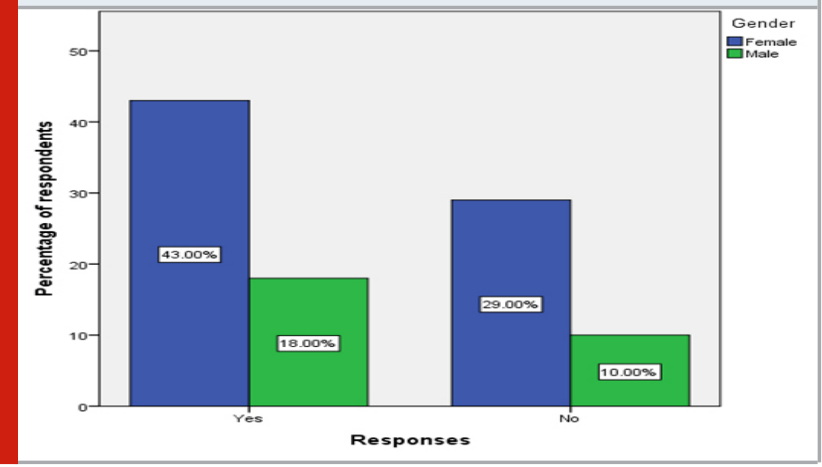

\section{RESULTS AND DISCUSSION}

The survey population consisted of 100 participants of which 72 were females and 28 were males. Fig 1.The first question of the survey was if family history had a significant etiological association in the causation of oral cancer. $61 \%$ of the respondents believed that family 
history does cause oral cancer. In this group, 43\% were females and 18\% were males.Fig2.Following question was asked about the important risk factor that was involved in oral cancer, where about 59\% of the students chose tobacco chewing, whereas remaining of them claimed that it was of alcohol (5\%), family history (2\%) and HPV (34\%), as shown in Fig3. The next question was on the site of oral cancer, where $71 \%$ of the dental students answered the most common site of oral cancer which is the labial or buccal mucosa. However, remaining 16\%, $2 \%, 3 \%$ and $7 \%$ assumed that it was tongue, gingiva, palate and alveolar mucosa, respectively.

Figure 3: Bar graph showing association between the risk factor of oral cancer and the gender of the participants. The great majority of the respondents were for tobacco followed by HPV. A Chi-square association between the gender and the response $(1.194 \mathrm{p}-0.74(\mathrm{p}>0.05))$ which is not statistically significant implying no association between the gender and the nature of response.

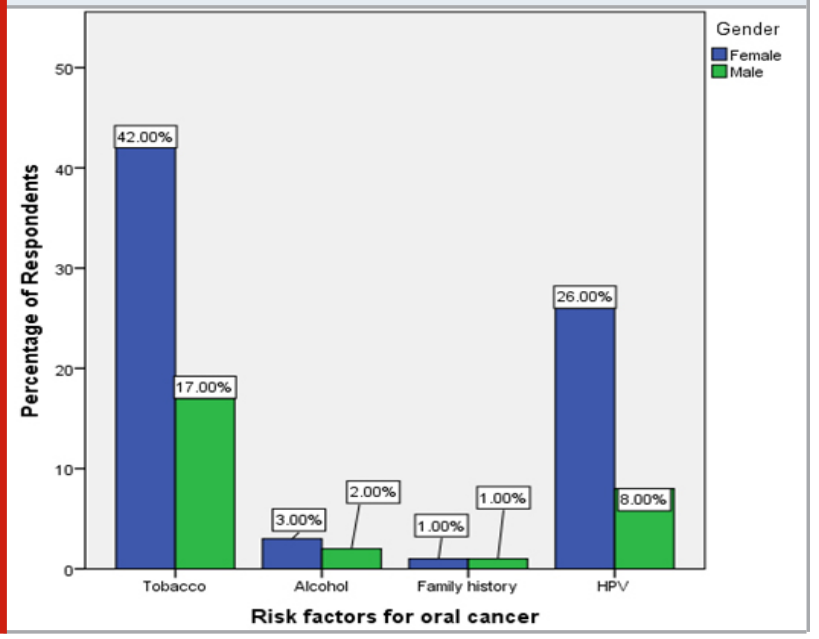

Figure 4: Bar graph showing association between the common site of oral cancer and the gender of the participants. $74 \%$ of the respondents felt that labial and buccal mucosa was the predominant site for the oral cancer. A Chi-square association between the gender and the response $(0.693 \mathrm{p}-0.04(\mathrm{p}<0.05))$ which is statistically significant implying an association between the gender and the nature of response.

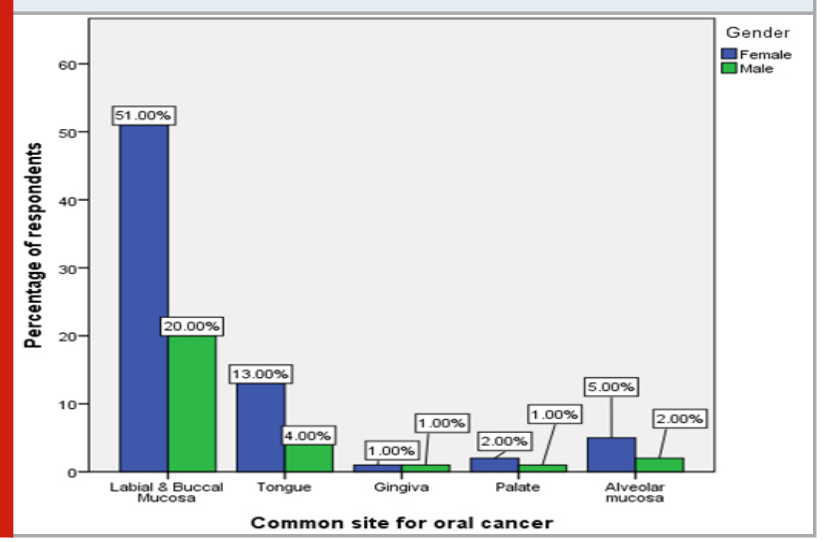

There was a statistically significant association between the gender and the nature of the responses $(\mathrm{P}<0.05)$ which was statistically significant. Fig 4. The next question on awareness was to check if the students routinely gave information regarding the awareness of etiological factors in the causation of oral cancer. For this question $76 \%$ of the respondents said they inform the patients about the risk factors of oral cancer if noted during a routine clinical examination. Fig 5 . The next question assessed the awareness of students on the most common presenting symptom of oral cancer which showed that majority (61\%) of the students answered saying the important clinical features of oral cancer by choosing white or red patches. Remaining 35\% and $4 \%$ chose difficulty in swallowing and lump in mouth, respectively.

Figure 5: Bar graph showing association between the dissemination of information on oral cancer and the gender of the participants. 76\% of the respondents felt that information on oral cancer was passed on the patients during routine history taking. A Chi-square association between the gender and the response $(0.446$ $\mathrm{p}-0.72(\mathrm{p}>0.05))$ which is statistically not significant implying no association between the gender and the nature of response.

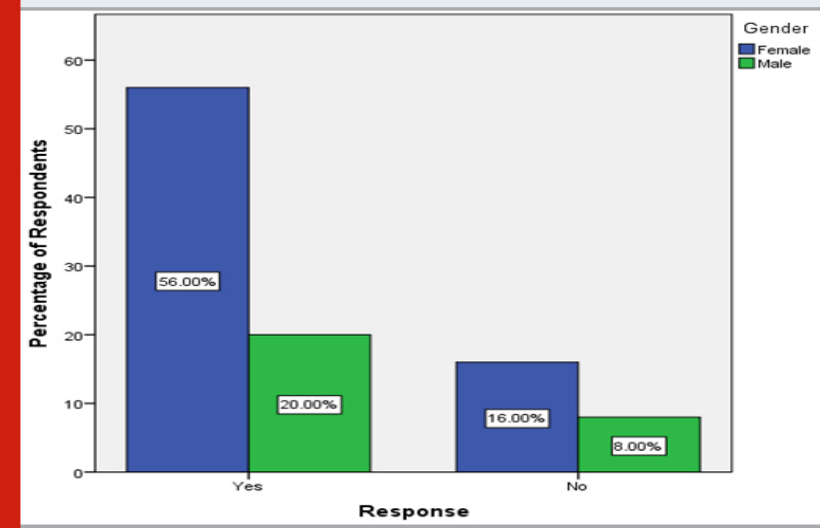

Figure 6: Bar graph showing association between the awareness on the symptoms of oral cancer and the gender of the participants. Majority of of the respondents felt that oral cancer presents itself as a red/white patch. A Chi-square association between the gender and the response(2.336 p-0.311(p>0.05)) which is statistically not significant implying no association between the gender and the nature of response.

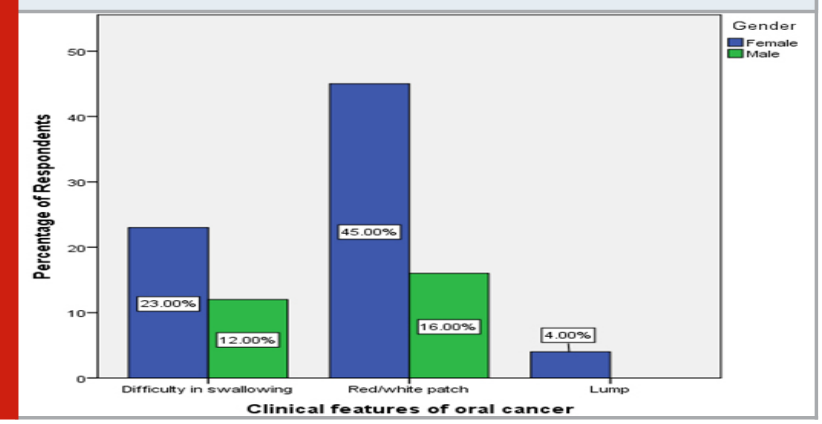


Figure 7: Bar graph showing association between the awareness on the role of HPV in oral cancer and the gender of the participants. Majority of of the respondents felt that HPV can cause oral cancer.. A Chi-square association between the gender and the response $(0.511 \mathrm{p}-0.04(\mathrm{p}<0.05))$ which is statistically significant implying association between the gender and the nature of response.

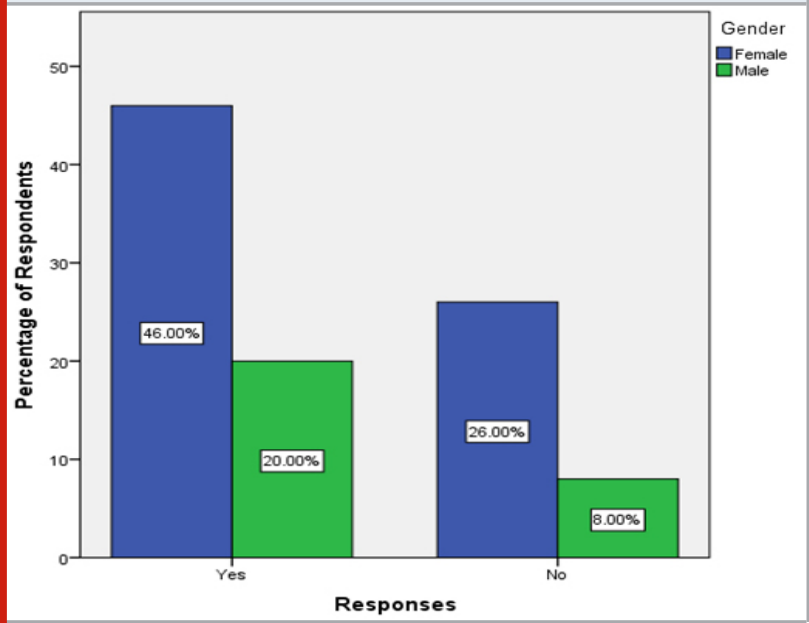

Figure 8: Bar graph showing association between the symptoms of HPV and the gender of the participants. Majority of of the respondents felt that HPV can cause oral cancer.. A Chi-square association between the gender and the response(6.932 p-0.07(p>0.05)) which is statistically not significant implying no association between the gender and the nature of response.

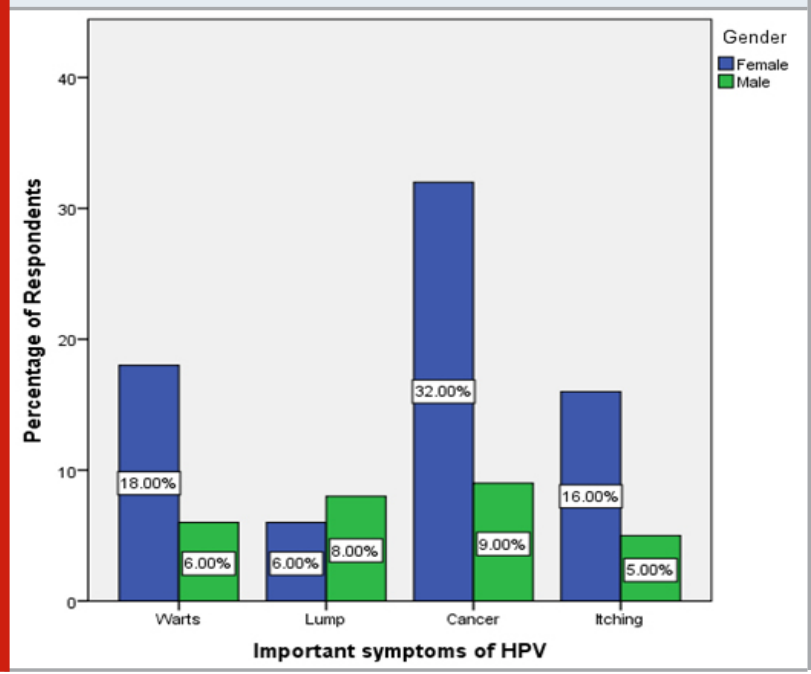

In figure 7 we read the responses to the question asked about awareness on the role of HPV in oral cancer, where $66 \%$ of the students are aware of it. Remaining 34\% of them were not aware of the role of HPV in oral cancer which was statistically significant $(p<0.05)$ Question number 8 was asked about important symptoms of HPV, majority (41\%) chose cancer and remaining of them chose warts (24\%), lumps (14\%) and itching (21\%). Figure 8 The majority of the students (45\%)chose cryotherapy as the treatment of choice for HPV, whereas remaining 28\% and
$27 \%$ chose chemotherapy and radiotherapy respectively as shown in figure 9.According to figure 10 , only $61 \%$ of dental students answered correctly regarding the important screening aids for oral cancer, which is oral brush biopsy. Remaining of them chose vital staining (20\%), Auto-Fluorescence (10\%) and chemiluminescence (9\%).. The final question was asked about the opinion of dental students regarding the first person to identify oral cancer.

Figure 9: Bar graph showing association between the treatment of HPV and the gender of the participants. Majority of of the respondents felt that cryotherapy is the best treatment for oral cancer. A Chi-square association between the gender and the response(4.469 $\mathrm{p}-0.72(\mathrm{p}>0.05))$ which is statistically not significant implying no association between the gender and the nature of response.

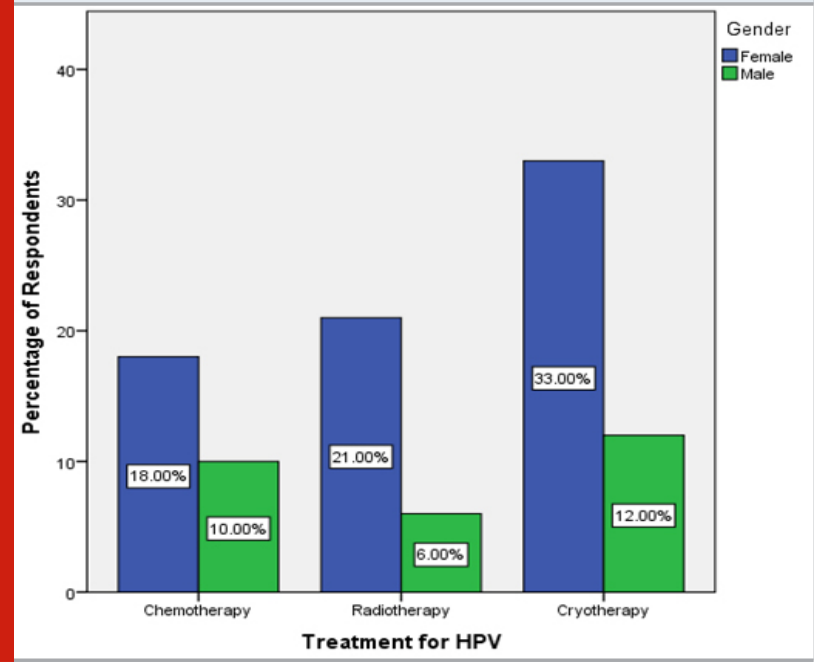

Figure 10: Bar graph showing association between the screening aids of oral cancer and the gender of the participants. Majority of of the respondents felt that brush biopsy is the best screening tool for oral cancer. A Chi-square association between the gender and the response(5.125 $\mathrm{p}-0.95(\mathrm{p}>0.05))$ which is statistically not significant implying no association between the gender and the nature of response.

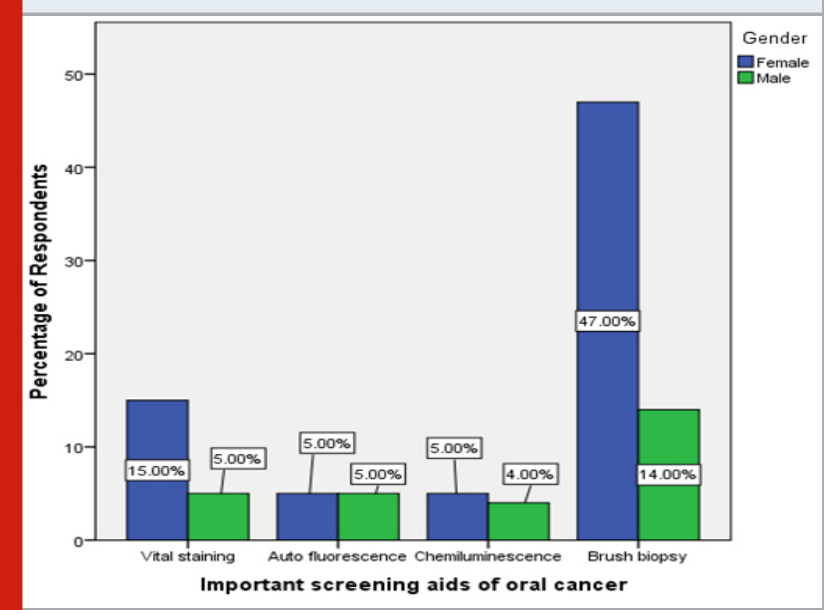


Here, about $71 \%$ agreed that it is a dentist to identify first, whereas 29\% of them disagreed with the statement. Fig 11 In a study by Avinash et al.,(Jnaneswar et al. 2017) identified that their students are aware of tobacco chewing was proved it as the most important avoidable factor of oral cancer. The known risk factors for oral cancer are tobacco use and alcohol consumption. Identifying patients' tobacco and alcohol use, whether current or past, is crucial for a practitioner to be knowledgeable about his or her patient's risk of developing oral cancer. According to a portfolio by WHO in 2016, infection with certain types of human papillomavirus has also been linked to oral cancer. Owing to the multitude of causes that could possibly hinder the prognosis, early detection is, thus, crucial(Sankaranarayanan et al. 2016).

Figure 11: Bar graph showing association between the awareness of dentist on oral cancer and the gender of the participants. Majority of of the respondents felt that dentists are the first person to report on oral cancer. Chi-square association between the gender and the response $(0.03 p-0.75(p>0.05))$ which is statistically not significant implying no association between the gender and the nature of response.

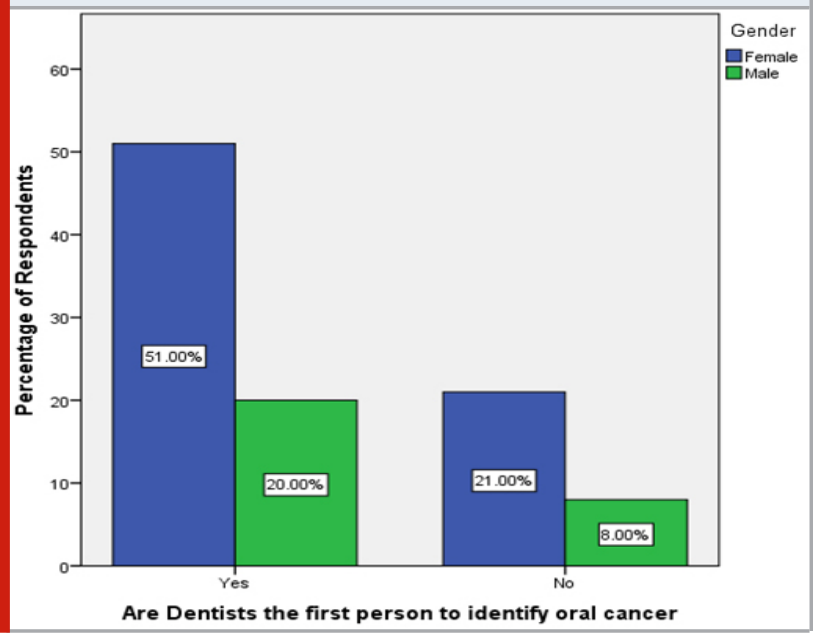

In a literature by Khan et al.,(Khan 2012) showed that the count of oral cancer in South Asia are up to 40\% of all cancers. However, in India, the incidence of oral cancer is about 3-7 times more common as compared to resource-rich countries. They also emphasized that in India the prevalence of oral cancer is high than the rest of the world. Oral cancer is the third most common cancer in India after cervical and breast cancer among women. The age-standardized incidence rate of oral cancer is reported at 12.6/100,000 people.

The increased prevalence of oral cancer in the Indian subcontinent seems to be due to the heavy usage of tobacco in the form of smoking, and other smokeless tobacco habits, alcohol, spicy food, and neglect of overall oral health. It is said that one-third of all oral cancers are preventable and one-third of them occur due to risk factors.Moreover in study conducted by
Coelho et al.,(Coelho 2012) in the United States, for example, tobacco in the form of snuff and chew and certain lifestyle and environmental factors do pose as risk factors.

Early detection and diagnosis of this disease spectrum by not only the dental practitioners, but also by the medical practitioners is therefore of utmost importance in its successful treatment, and thus directly affecting prognosis. In a study carried out by Carter et al., (Lachlan M. Carter and Ogden 2007) revealed that the individuals at greatest risk for oral cancer rarely visit a dental practitioner but do consult general medical practitioners and thus concluded that these practitioners could play an important role in the early detection of oral cancer. Thus, it is important for dental practitioners as well to be knowledgeable regarding oral cancer.

Another similar study by Ogden et al.,(L. M. Carter and Ogden 2007) showed that dental practitioners had a higher score for knowledge and practice questions. Interestingly, they also had a better attitude than medical practitioners regarding oral cancer. This may be attributed to the fact that professional courses that familiarize them with the more common and important oral diseases enhance their diagnostic abilities than the medical practitioners. A survey by Sitheeque et al,(Sitheeque, Ahmad, and Saini 2014) on awareness of oral cancer and pre-cancer among final year medical and dental students of Universiti Sains Malaysia showed the dental students had better knowledge in some key areas which were different from their medical colleagues. The authors pointed to a necessity to strengthen these aspects of medical and dental undergraduate curriculum.

Similar studies were done by Alami et al,(Alami, El Sabbagh, and Hamdan 2013) to assess the knowledge of oral cancer among recently graduated dental professionals in Amman, Jordan. The results revealed an inadequate level of knowledge of oral cancer among the study population. Das et al,(Das and Patro 2010) in his article stresses on the increase in efforts to expand the resources for health education and increase awareness of cancer prevention to the people and health care providers with an unprecedented level of cooperation among international agencies, government and nongovernmental organizations, international foundations, healthcare system and local institutions can help us control the incidence of new cases.

\section{CONCLUSION}

Within the limitations of this study, we find the majority of the dental students were aware of the term oral cancer. There needs to be an improvement in the depth of knowledge pertaining to HPV virus.Further, study should be conducted in a larger scale area and sample size to get a proper overview regarding this topic within the general public concerning the new advent technologies. 


\section{ACKNOWLEDGEMENTS}

The authors would like to thank the Management of Saveetha Dental College for providing us the encouragement and permission to carry out the study.

Conflict of Interest: The authors declare that this is a self funded study and there is no conflict of interest.

\section{REFERENCES}

Agrawal, Mamta, Sushma Pandey, Shikha Jain, and Shipra Maitin. 2012. "Oral Cancer Awareness of the General Public in Gorakhpur City, India.” Asian Pacific Journal of Cancer Prevention: APJCP 13 (10): 5195-99.

Alami, Arwa Yousef, Rula F. El Sabbagh, and Abdelhameed Hamdan. 2013. "Knowledge of Oral Cancer among Recently Graduated Medical and Dental Professionals in Amman, Jordan.” Journal of Dental Education 77 (10): 1356-64.

Ariyawardana, A., and N. Vithanaarachchi. 2005. "Awareness of Oral Cancer and Precancer among Patients Attending a Hospital in Sri Lanka." Asian Pacific Journal of Cancer Prevention: APJCP 6 (1): 58-61.

Carter, Lachlan M., and Graham R. Ogden. 2007. "Oral Cancer Awareness of Undergraduate Medical and Dental Students.” BMC Medical Education 7 (November): 44. Carter, L. M., and G. R. Ogden. 2007. "Oral Cancer Awareness of General Medical and General Dental Practitioners.” British Dental Journal 203 (5): E10; discussion 248-49.

Coelho, Ken Russell. 2012. "Challenges of the Oral Cancer Burden in India.” Journal of Cancer Epidemiology 2012 (October): 701932.

Das, S., and K. C. Patro. 2010. "Cancer Care in the Rural Areas of India: A Firsthand Experience of a Clinical Oncologist and Review of Literatures." Journal of Cancer Research and Therapeutics 6 (3): 299-303.

Hassona, Yazan, Crispian Scully, Mais Abu Ghosh, Zaid Khoury, Shadi Jarrar, and Faleh Sawair. 2015. "Mouth Cancer Awareness and Beliefs among Dental Patients." International Dental Journal 65 (1): 15-21.

Jemal, Ahmedin, Rebecca Siegel, Jiaquan Xu, and Elizabeth Ward. 2010. “Cancer Statistics, 2010." CA: A Cancer Journal for Clinicians 60 (5): 277-300.

Jnaneswar, Avinash, Bala Subramanya Goutham, Jayashree Pathi, Kunal Jha, Vinay Suresan, and Gunjan Kumar. 2017. “A Cross-Sectional Survey Assessing Knowledge, Attitude, and Practice Regarding Oral Cancer among Private Medical and Dental Practitioners in Bhubaneswar City.” Indian Journal of Medical and Paediatric Oncology: Official Journal of Indian Society of Medical \& Paediatric Oncology 38 (2): 133-39.
Khan, Zahid Ullah. 2012. "An Overview of Oral Cancer in Indian Subcontinent and Recommendations to Decrease Its Incidence." https://www.webmedcentral. com/article_view/3626.

Kumar, Malay, Ronak Nanavati, Tapan G. Modi, and Chintan Dobariya. 2016. "Oral Cancer: Etiology and Risk Factors: A Review.” Journal of Cancer Research and Therapeutics 12 (2): 458-63.

Monteiro, Luís Silva, Filomena Salazar, Júlio Pacheco, and Saman Warnakulasuriya. 2012. "Oral Cancer Awareness and Knowledge in the City of Valongo, Portugal.” International Journal of Dentistry 2012 (August): 376838.

Patil, Santosh Rayagouda, G. Maragathavalli, D. N. S. V. Ramesh, Sheeja Vargheese, Ibrahim A. Al-Zoubi, and Mohammad Khursheed Alam. 2020. "Assessment of Maximum Bite Force in Oral Submucous Fibrosis Patients: A Preliminary Study.” Pesquisa Brasileira Em Odontopediatria E Clinica Integrada, Histopathological studies before and after kepacort in oral submucous fibrosis, 20: 482.

Patil, Santosh R., G. Maragathavalli, Kazuyuki Araki, Ibrahim A. Al-Zoubi, Mohammed G. Sghaireen, Ravi Kumar Gudipaneni, and Mohammad Khursheed Alam. 2018. "Three-Rooted Mandibular First Molars in a Saudi Arabian Population: A CBCT Study.” Pesquisa Brasileira Em Odontopediatria E Clinica Integrada 18 (1): e4133. Patil, S. R., N. Yadav, I. A. Al-Zoubi, G. Maragathavalli, M. G. Sghaireen, R. K. Gudipaneni, and M. K. Alam. 2018. "Comparative Study of the Efficacy of Newer Antioxitands Lycopene and Oxitard in the Treatment of Oral Submucous Fibrosis.” Pesquisa Brasileira Em Odontopediatria E Clinica Integrada 18 (1): 1-7.

Prasad, Lingamaneni. 2014. "Burden of Oral Cancer: An Indian Scenario." Journal of Orofacial Sciences 6: 77.

Ramachandra, Naikbalachandra. 2012. "The Hierarchy of Oral Cancer in India." International Journal of Head and Neck Surgery 3 (3): 143-46.

Sankaranarayanan, Rengaswamy, Kunnambath Ramadas, Hemantha Amarasinghe, Sujha Subramanian, and Newell Johnson. 2016. "Oral Cancer: Prevention, Early Detection, and Treatment.” In Cancer: Disease Control Priorities, Third Edition (Volume 3), edited by Hellen Gelband, Prabhat Jha, Rengaswamy Sankaranarayanan, and Susan Horton. Washington (DC): The International Bank for Reconstruction and Development / The World Bank.

Sitheeque, Mohaideen, Zulkifli Ahmad, and Rajan Saini. 2014. "Awareness of Oral Cancer and Precancer among Final Year Medical and Dental Students of Universiti Sains Malaysia (USM), Malaysia.” Arch Orofac Sci 9: 53-64.

Srikanth Reddy, B., Dolar Doshi, M. Padma Reddy, Suhas 
Kulkarni, Abdul Gaffar, and Venkat Ram Reddy. 2012.

"Oral Cancer Awareness and Knowledge among Dental Patients in South India.” Journal of Cranio-Maxillo-

Facial Surgery: Official Publication of the European Association for Cranio-Maxillo-Facial Surgery 40 (6): 521-24.

Subramaniam, Nandhini, and Arvind Muthukrishnan. 2019. "Oral Mucositis and Microbial Colonization in
Oral Cancer Patients Undergoing Radiotherapy and Chemotherapy: A Prospective Analysis in a Tertiary Care Dental Hospital.” Journal of Investigative and Clinical Dentistry 10 (4): e12454.

Vadivel, Jayanth Kumar, Meera Govindarajan, Elangovan Somasundaram, and Arvind Muthukrishnan. 2019. "Mast Cell Expression in Oral Lichen Planus: A Systematic Review." Journal of Investigative and Clinical Dentistry 10 (4): e12457. 